«Дім, який побудував Джек» Дж. Л. Гейнор як зразок англомовної дитячої...

15. Krohn, E. (1924). A century of Missouri Music. [online] HathiTrust Digital Library. Available at: https://hdl.handle.net/2027/uc1.b4494993_[Accessed 3 Jun. 2018]. [in English].

16. Robinson Scott, W. (1887). History of the city of Cleveland. Altenmünster: Juzzybee Verlag Jürgen Beck, 250 p. [in English].

17. Watkins, W. (1937). Producing a school operetta. Music Educators Journal, [online] 24 (1), pp. 43-46. Available at: https://www.jstor.org/stable/3385497 [Accessed 11 Jan. 2019]. [in English].

Стаття надійшла до редакиіiї 16.01.2019 p.

УДК 782.1.071.1:792.071.2(450)

ORCID 0000-0001-7859-0870

\title{
Адиля Мизитова
}

Харьковский национальныий университет искусств

имени И. П. Котляревского

«ТУРАНДОТ» ДЖ. ПУЧЧИНИ

ГЛАЗАМИ МАРКО МАРЕЛЛИ

Мизитова А. А. «Турандот» Дж. Пуччини глазами Марко Марелли. Рассмотрена постановка оперы «Турандот» Дж. Пуччини, осуществлённая швейцарским режиссёром и оформителем Марко Марелли на оперной сцене Боденского озера в 2015 году (г. Брегенц, Австрия). Выявлено влияние особых условий игровой площадки на создание визуально-декоративного ряда. Отмечена двуплановость содержательного уровня режиссёрской концепции, которая реализована благодаря введению парной фигуры Пуччини - Калаф. Эта идея возникла в результате глубокого изучения событий в жизни композитора, в том числе в период создания последнего оперного полотна, и проблем сугубо творческого характера. Раскрыты способы реализации психологической компоненты произведения при огромных масштабах сцены, исключающих возможность показа исполнителя крупным планом; подчёркнута роль метаморфоз маски немого кино А. Китцига в создании символической линии спектакля. Приводятся сведения о разных интерпретациях сказочного сюжета, позволяющих понять индивидуальность композиторских намерений.

Ключевые слова: опера, режиссёрская концепция, двуплановость содержания, маска, игровая площадка, визуально-декоративный ряд. 
Мізітова А. А. «Турандот» Дж. Пуччіні очима Марко Мареллі. Розглянута постановка опери «Турандот» Дж. Пуччіні, яку здійснив швейцарський режисер і оформлювач Марко Мареллі на оперній сцені Боденського озера у 2015 році (м. Брегенц, Австрія). Виявлено вплив особливих умов ігрової площадки на створення візуально-декоративного ряду. Відзначена двоплановість змістовного рівня режисерської концепції, реалізована завдяки уведенню парної фігури Пуччіні Калаф. Ця ідея виникла як результат глибокого вивчення подій у житті композитора, зокрема за період створення останнього оперного полотна, та проблем суто творчого характеру. Розкриті засоби реалізації психологічної компоненти твору на чималих масштабах сцени, які виключають можливість показу виконавця великим планом; підкреслена роль метаморфоз маски німого кіно А. Кітціга при створенні символічної лінії вистави. Наводяться відомості про різні інтерпретації казкового сюжету, що дозволяе зрозуміти індивідуальність композиторських намірів.

Ключові слова: опера, режисерська концепція, двоплановість змісту, маска, ігрова площадка, візуально-декоративний ряд.

\section{Mizitova A. A. Marko Marelli's vision of "Turandot" by Giacomo Puccini.}

Background. As a notion, an opera theater led by a stage director has a strong presence in modern artistic practice, as it puts forward its own range of cognitive and evaluative tasks that undergo criticism. The first task is related to compliance of the proposed rendition with the composer's concept and music drama of a particular opera music piece. The second one is related to the director's vision and understanding the peculiarities, which allows us to form an opinion about the comprehension degree of an author's idea and the individuality of its implementation. The relevance of the designated semantic constants is reinforced by the variety of opera classics incarnation on famous opera stages.

Objectives. The purpose of the article is to study and analyze the scenographic techniques that allow M. Marelli with his bright talent as a director to embody the opera plot and uncover incentive-psychological motifs that define the deep content layer of G. Puccini's "Turandot" opera.

Methods. The study is based on a comparative method of analysis, with the help of which the validity of M. Marelli's directorial concept by the dramatic concept and the semantic lines peculiarities of G. Puccini's opera is revealed.

Results. The stage performance of "Turandot" by G. Puccini on the famous opera stage of the Lake Constance was timed to coincide with the $70^{\text {th }}$ anniversary of the Bregenz festival. For the implementation of this project, the Swiss stage director and designer Marco Arturo Marelli was invited for the first time to organize it. The specific features of the huge stage forced all the natural conditions to be considered: wind, water, its level, and the weight of the theatrical scenery elements. Therefore, before creating the intended environment, M. Marelli built several preliminary models in search of the only solution that would combine the oriental flavor and plot intrigue, hidden psychologism and bare emotions, intimacy and pompous mass scenes. The dramatic composition of 
the scenario, created by M. Marelli, makes it possible to tell how deep his comprehension of Puccini's music is, as we observe its semantic components and the interaction of contrasting figurative lines, author's remarks in the score, personal circumstances in the composer's life, his letters, the conditions for creating an opera and a long search of ways to cut the knot of plot contradictions in the Finale part. The techniques he used reveal his artistic and aesthetic principles. This allowed him to create an organic fusion of intense musical and dramatic action, defused by ensemble, choral and dance scenes, visual effects that decode psychological subtext, and the theatrical scenery itself, which specifies the exact place of events, complements the missing verbal commentary, allowing the stage area to look massive and versatile. As a result, the ideological concept of M. Marelli appears in the interdependence of the internal and external planes; their content is determined by his understanding and vision of the opera "here and now", that is, as a single musical and theatrical piece. The internal plane is directly connected with the events of the fairy-tale plot, interpreted by the stage director's individual consciousness. The external one forms the design of the performance through the variety of static and mobile forms, transformed according to the sequence of light effects, and the silent video by A. Kitzig, which gives a slight expressionistic taste. M. Marelli's intellectual and emotional immersion in the "history" of the opera contributed to the formation of a symbolic by-plot through two figures: Puccini and Calaf (a character of the opera). It is played on a small platform at the bottom of the main stage, depicting the "blue room" (O. Schmitt), where you can see the instrument with the scores on the music stand, a table with a jewel-box on it, an armchair, and a bed. The man that appears clearly personifies the composer, who "looks for" music ideas. As the events are unfolding, Calaf appears in the "room"; he is tormented by the desire to melt the cold heart of Turandot and feverishly looking for a way out of this situation. The novelty of interpreting a well-known fairy-tale plot lies in a fundamentally different motivation for the behavior of Turandot. She identifies herself with Lou-Ling, who was tortured and murdered by a man long ago, so Turandot is driven by a thirst for revenge. The story about the cry of the miserable princess Turandot, which she constantly hears inside of her, looks differently as if she becomes one with her distant ancestor. By the end of the story, she appears as in a cocoon shell, unattainable and invincible. This is followed by a scene of puzzles that move events to a turning point in the plot twists and turns and mark a kind of a going-back flow of time. The director increases of effect of the symbolic line in the performance by adding the silent video by A. Kitzig. The parallel dynamics of the stage action and the metamorphosis of the masks visualizes the psychological component of Puccini's opera. The whole set of plot and scenery means exists only with the purpose of revealing this psychological component. As a result, the scene of the test Calaf must pass acquires a different dimension, delineating the fate twists of both heroes. Again and again, the pieces of clothes fall down from Turandot like scales of a snake. This is accompanied by the transformation of the previously unfired face of the mask, which ultimately cracks like a clay cast and finally collapses. The heroine remains in a thin 
silky dress shirt and tries to cover her bare shoulders with her hands. Her nakedness is akin to defenselessness, the loss of solid ground under your feet. This way, M. Marelli resolved not only the problem of the impossibility to show a psychological degeneration of personality on the huge stage by traditional acting techniques, but also contradictions of plot twists that haunted the composer.

Conclusions. The experience of the Bregenz version shows that an important role played by the conditions of the stage space, which was used by a talented stage director and designer as a component of the multi-level system, where everything goes with accordance to the hierarchical subordination of the play. This seems to be the masterful combination of M. Marelli's personal artistic and aesthetic philosophy, the features of the last opera by J. Puccini and all theatrical resources of a unique theatrical scene of the Lake Constance.

Keywords: stage director's concept, two-plane nature of content, mask, stage area, visual and theatric scenery effects.

Постановка проблемы. Режиссёрский оперный театр, получивший развитие на волне острых дискуссий вокруг архаизации постановок классического наследия, прочно утвердился в современной художественной практике, выдвинув перед критикой свой круг познавательно-оценочных задач. Первая из них связана с соответствием предложенного решения композиторскому замыслу и музыкальной драматургии конкретного оперного образца. Вторая - с особенностями режиссёрского прочтения, позволяющими судить о степени постижения авторской идеи и индивидуальности её претворения. Актуальность обозначенных смысловых констант подкрепляется многообразием воплощения оперной классики на именитых оперных сценах.

Анализ последних исследований и публикаций. Трудов, специально посвящённых вопросам типизации режиссёрских подходов к сценическому воплощению оперной концепции, к сожалению, нет. Данный факт объясним несколькими причинами: отсутствием необходимой исторической дистанции, исследований индивидуального почерка конкретного режиссёра, его художественно-эстетических принципов с привлечением результатов уже осуществлённых проектов, сравнения постановок одной и той же оперы мастером на разных сценических площадках, его коллег по профессиональному цеху и т. п. В силу этого, музыковеды и музыкальные критики идут по пути накопления эмпирического материала, делая на его основе важные для осмысления современного положения дел умозаключения. Например, М. Черка- 
шина-Губаренко предлагает читателю многокрасочную, не лишённую полемичности повесть о бытии оперного театра в современном мире, опираясь на опыт мировых сцен и известных оперных фестивалей [3]. Отталкиваясь от тезиса, что «<..> оперный спектакль развёртывается на основе полифонического взаимодействия театрального, драматического и музыкального сюжетов», учёный приходит к выводу, что приметой современной оперной режиссуры становится «сочинение» спектакля как нового художественного текста [3:77-78]. «При этом, - пишет автор, - он трактуется именно как практика, процесс порождения нового смысла» [3:78]. Плодотворное влияние «режиссёрского театра» на оперное искусство отмечает М. Нестьева [2]. Не оставляя без внимания перекосы, порождённые игнорированием специфики оперы как «лирического театра», известный музыкальный критик противопоставляет им подлинные открытия в области сценарной драматургии. За каждым из них, помимо таланта и эрудиции режиссёров, ощутим пиетет к музыке, её высокому слогу чувств и особенностям высказывания. Как видно, проблема «опера - режиссура» имеет открытый характер и ставит перед исследователем необходимость поиска ключа для раскрытия сложного переплетения смыслообразующих нитей, объединяющих в единичном сценарном решении композиторскую и режиссёрскую концепции.

Цель статьи видится в реконструировании сценографических приёмов, позволяющих режиссёру М. Марелли воплотить оперный сюжет и раскрыть побудительно-психологические мотивы, определяющие глубинный слой содержания «Турандот» Дж. Пуччини.

Изложение основного материала. Появления «Турандот» Дж. Пуччини на знаменитой оперной сцене Боденского озера с нетерпением ожидали два года, ведь оно было приурочено к 70-летию Брегенцского фестиваля. Напомним, что этот форум искусства возник после второй мировой войны, в 1946 году. По словам федерального президента Хайнца Фишера, открывшего торжества, его ключевым мотивом стала идея свободы, мира и человеческого достоинства [4:4], которая и сегодня не утрачивает своей актуальности. Размышляя о пройденном пути, оратор заметил, что вряд ли в то далёкое время можно было представить, что в 2015 году Брегенцский фестиваль «станет лучшим во всём мире» [там же]. Этому успеху способствуют не только прекрасный ландшафт, придающий событиям уникальный 
колорит, превосходные исполнители, но и художественное руководство, на плечи которого ложится нелёгкая задача определять «различия между “хорошо” и “превосходно”» [там же].

Для осуществления фестивального оперного проекта впервые в Брегенц был приглашён швейцарский режиссёр и оформитель Марко Артуро Марелли (Marco Arturo Marelli). Его опыт по созданию сценографии меняет привычные представления о простом переносе ранее осуществлённой постановки на новую театральную площадку. Специфика огромной сцены, по его словам, комплексной и сложной, диктовала необходимость учитывать все природные условия: ветер, воду, её уровень, вес декорационных конструкций [5:10]. Поэтому, прежде чем приступить к реализации задуманного, М. Марелли построил несколько предварительных моделей в поисках того единственного решения, в котором соединялись ориентальный колорит и сюжетная интрига, скрытый психологизм и обнажённая драма чувств, интимность и пышность массовых сцен. В интервью талантливый режиссёр-декоратор признался, что «Брегенц является всегда большим вызовом» [6:8], но его техническая оснащённость ничем не сковывает фантазию художника. Разрабатывая концепцию спектакля, он оценивал сцену со стороны зрительских рядов, постепенно оживляя в воображении сказку о пекинской принцессе. Так появились: китайская стена, изгибы которой напоминают дракона; фигуры терракотовых воинов, словно выходящих из воды; вращающийся цилиндр с 16-тиметровым диаметром в центре сценической площадки, меняющий «интерьер» повествования и вмещающий при необходимости 54 исполнителя; кораблик, украшенный балдахином и фонариками, на котором проплывает жестокосердная красавица; финальные торжественно-ликующие фонтаны и многое другое, что неосуществимо даже в самом современном в техническом отношении театральном здании. Вместе с тем, М. Марелли рассматривал зрелищность лишь средством для выражения музыкального содержания. Грозные громоподобные аккорды, открывающие оперу Дж. Пуччини, сопровождаются разрушением части стены, обнажающей несгибаемую терракотовую армию - неизменный атрибут императорской власти. Предваряя «речь» Мандарина, в который раз зачитывающего указ о необходимости претенденту на руку и сердце Турандот разгадать три её загадки, такой театральный эффект становится символом крушения не 
только надежд потерпевших неудачу и поплатившихся за это жизнью, но и самой, казалось бы, всемогущей принцессы.

Сценарная драматургия, созданная М. Марелли, позволяет судить о глубине постижения им музыки Дж. Пуччини во всей совокупности её смыслообразующих компонентов и взаимодействии контрастных образных линий, авторских ремарок в партитуре, личных обстоятельств в жизни композитора, его писем, условий создания оперы и долгого поиска способа разрубить узел сюжетных противоречий финала. Избранные режиссёром приёмы в полной мере выявляют его художественноэстетические принципы, благодаря которым возник органичный сплав напряжённого музыкально-драматического действия, разряжаемого ансамблево-хоровыми и танцевальными сценами, визуального ряда, дешифрующего психологический подтекст, и собственно декораций, конкретизирующих место событий, восполняющих отсутствующий словесный комментарий, придающих игровой площадке объёмность и многоплановость. В результате идейная концепция М. Марелли предстаёт во взаимообусловленности внутреннего и внешнего планов, чьё наполнение определяется его пониманием-ви́дением оперы «здесь и сейчас», то есть как единичного музыкально-театрального произведения. Внутренний план непосредственно связан с событийностью сказочного сюжета, преломлённого сквозь индивидуальное сознание постановщика. Внешний - образует оформление спектакля в многообразии статичных и мобильных форм, преображаемых согласно световой партитуре, и немого, по-экспрессионистски заострённого видео А. Китцига (Aron Kitzig).

Судя по высказываниям М. Марелли, которые приводит в своей статье О. Шмитт (Olaf A. Schmitt) [9], при разработке содержания сценической драматургии он исходил из того, что последняя опера великого мастера страстных любовных историй несёт на себе печать роковых обстоятельств его жизни. Общеизвестно, что в период написания «Турандот» у Дж. Пуччини обострилась болезнь горла, потребовав вмешательства онколога. На момент переезда композитора в брюссельскую клинику заключительный дуэт главных героев и финал последнего действия оставались в набросках. Но именно их композитор считал важнейшими кульминационными точками всей оперы. О. Шмитт приводит выдержку из его письма, написанного за два месяца до смерти: «Это 
должен быть большой дуэт. Эти оба существа, которые, так сказать, стоят вне этого мира, возвращаются благодаря любви в общество, и эта любовь должна [...] захватить всех персонажей на сцене» (цит. по: [9:25]). Так в чём же заключалась суть проблемы в решении этих узловых моментов, учитывая многолетнюю успешную практику Дж. Пуччини как оперного драматурга? - В судьбе беззаветно влюблённой в принца Калафа невольницы Лиу, которая введена в либретто вместо Адельмы К. Гоцци и является её антиподом. Режиссёр считал, что этот образ навеян реальными трагическими событиями: «После тяжёлой автомобильной катастрофы, в которую попал Пуччини, - пояснял М. Марелли, - на виллу Torre del Lago была принята сиделкой и помощницей по домашнему хозяйству шестнадцатилетняя Дория Манфреди. Пуччини испытывал определённую симпатию к простой девушке. Его жена Эльвира заподозрила неладное и начала невинную Дорию ругать и публично чернить как распутницу. Вся деревенская округа < .. > была втянута в этот конфликт, и бедная девушка не знала иного выхода, как покончить с собой крайне мучительным способом» (цит. по: [10:59]). Смерть оперной героини, закалывающей себя ради сохранения тайны любимого, практически сводила «на нет» возможность счастливой развязки основного сюжета. Понимал это и композитор, который, по словам режиссёра, размышлял над тем, чтобы «очеловечивание», то есть обоюдное приятие любви, главных персонажей выразить оркестровыми средствами [9:23]. Этим замыслам не дано было осуществиться, а Франко Альфано, завершивший оперу по оставленным наброскам, руководствовался желанием Дж. Пуччини прославить преображающую силу любви.

Интеллектуально-эмоциональное погружение М. Марелли в «историю» оперы способствовало формированию сюжетно-символической интриги с парной фигурой Пуччини - Калаф. Она разыгрывается на небольшой платформе, выступающей снизу основной сцены, изображающей «голубую комнату» (О. Шмитт), где находятся инструмент с нотами на пюпитре, столик со шкатулкой, кресло, кровать. Появляющийся мужчина явно олицетворяет композитора, «ищущего» музыкальные идеи. Потом он открывает шкатулку, из которой доносятся мелодичные звуки. Как сообщают исследователи, подобная механическая безделица была привезена бароном Эдуардо Фассини Камосси из Пекина и послужи- 
ла «важным толчком для оперы» Дж. Пуччини [9:24]. Композитор был настолько ею восхищён, что не только позаимствовал из её «репертуара» три мелодии, но и привёл обоих либреттистов порадоваться этому чудесному изобретению вместе с ним ${ }^{1}$. О неожиданном «прозрении» композитора в постановке М. Марелли сигнализирует звучание оркестра - опера начинается. По ходу же развёртывания событий в «комнате» оказывается Калаф, мучимый желанием растопить сердечный лёд Турандот и лихорадочно ищущий выхода из сложившейся ситуации. Режиссёр делился в интервью важными для него моментами в инсценировке оперы, проливающими свет на побудительные причины введения отсутствующей в основном сюжете смысловой линии. По его мнению, сказка исчерпывается во втором действии. «Она состоит из трёх загадок, - напоминает постановщик, - он (Калаф - А. М.) выигрывает, и счёт становится 1:0 в его пользу, но это нехорошая предпосылка для совместной жизни. И поэтому он пробует ей (Турандот - А. М.), замкнувшейся в себе, поставить вопрос о его собственном «Я». “Скажи мне моё имя, и имя есть любовь”. После того, как Пуччини лично пережил в известной степени похожую историю, и произведение также не могло быть завершено, соединились эти судьбы. Он хотел решить не только загадку этой женщины, но и загадку этой оперы, и таким образом отпечаталась фигура композитора на Калафе. Эта двусмысленность меня очень заинтересовала» [6:8]. Поэтому пуччиниевская нерешённость финала отождествляется в постановке с проблемами главного героя.

Крупномасштабное оперное полотно М. Марелли декорирует в духе постимпрессионистической живописи с её контрастным сосуществованием насыщенных красок, дополненных искрами огня и мечей, танцами извивающихся на шестах драконов, яркими фонариками, игрой белочёрного пространства и бликами небесно-водной глади угасающего летнего вечера. Автор костюмов К. Хоффман (Constance Hoffman) «вторит» декоратору, идя по пути смешения стилей: костюм с платком-галстуком, длинный плащ у Калафа выдают в нём современного человека; вечерние

${ }^{1}$ Несколько иную информацию даёт И. Нестьев без ссылок на источники. В частности автор пишет: «Сюжет “Турандот" вновь дал повод Пуччини ввести в оперу причудливый национальный колорит, на этот раз китайский. Он внимательно изучал подлинные народные мелодии Китая, слушал редкие фонограммы, предоставленные ему Британским музеем» [1:130-131]. 
наряды у ночной гуляющей толпы напоминают моду 20-х годов прошлого века; три министра, пришедшие из итальянской commedia dell'arte, носят пёстрые одежды и маски; преданная Лиу словно вышла из бедных кварталов времён экономического застоя. Император Альтоум облачён в белоснежные одежды, соответствующие его возрасту: несмотря на отсутствие жёлтого цвета - знака императорского отличия, и кресло-каталку вместо трона, внутренняя сторона поднятой крышки цилиндра озарена лучами солнца, сменяющимися огненно-красным драконом на тёмно-синем фоне; огромная масса статистов-клонов возрождают представления о периоде правления Великого кормчего. Только для Турандот приготовлен разнообразный гардероб, который непосредственно связан с развитием коллизий и отражает смену её психологического состояния. Чтобы понять логику движения мысли художников-оформителей, необходимо уточнить те изменения, которые претерпели древние мотивы в опере Дж. Пуччини.

О. Шмитт посвящает метаморфозам сюжета специальную статью, обозначая в самом названии его путь от праистоков до современности: «От Турандохт к Турандот. Превращения одной сказки» [10]. Среди ранних прообразов героини, вдохновивших не одно поколение поэтов и драматургов, автор называет русскую принцессу Турандохт, которая чётко обозначила четыре условия для мужчины, желающего взять её в жёны: «<..> он должен быть знатным и прекрасным; <..> сломать волшебный меч, который преградит ему дорогу; <.. > найти ворота, которые его ко мне приведут <...; и, наконец, <...> разгадать загадки, которые я ему буду задавать во дворце и в присутствии моего отца. Если он также разгадает и эти, то получит мою руку и с ней эликсир блаженства - но он должен дать мне правильный ответ. Иначе лишится своей жизни» (цит. по: [10:57]). Музыковед считает эти требования практически невыполнимыми (на то, заметим, это и сказка). Вместе с тем, сказочное повествование утвердилось в культурном пространстве, меняя со временем характеристику персонажей, окружение, вид загадок и т. п. По сведениям О. Шмитта, оно было записано персидским поэтом Низами (ок. 1141 - ок. 1209), который привнёс в него новые детали: его красавица отличалась умом и магическими силами, любила одиночество, уединённо жила в замке на горной вершине, но фигуры из железа 
и камня с мечом в руке всё ж указывали дорогу к её обители. Да и к «ультимативному» тексту прилагался, оказывается, её автопортрет, очевидно, с тем, чтобы претендент знал, кого хочет завоевать. Как замечает исследователь, «<..> в этой ранней версии есть портрет принцессы, притягивающий мужчин» [там же]. К. Гоцци воспринял более поздний вариант из собрания «Тысяча и один день», в котором Калаф испытывал ненависть к жестоким прихотям принцессы, но увидев её изображение, готов был на всё ради неё. Между тем, в пересказе Франсуа Пети де ла Круа (1653-1713) ключевой фигурой является принц, у К. Гоцци, как и у Низами, инициатива передана главной героине.

На изменениях фабулы сказалась и «полемика» итальянского драматурга со своим театральным соперником К. Гольдони, чьи просветительские устремления он подвергал нападкам. К. Гоцци искренне верил в то, что публика должна получать удовольствие и, одновременно, усваивать моральные устои. Достигал он этого в сотрудничестве с труппой Сакки, удерживающей традицию commedia dell'arte. Поэтому для К. Гоцци масочные персонажи - Панталоне, Тарталья, Бригелла, Труффальдино - с их искромётными шутками, снижающими комментариями, перепалкой были естественными фигурами, независимо от иного национального колорита сюжета. Дж. Пуччини сохраняет некоторые из них при смене социального статуса и имён на quasi китайские (Пинг, Панг, Понг). Об их роли в драматургии оперы можно судить по масштабной ансамблевой сцене, занимающей первую картину второго действия. В то же время, благодаря им история любви приобрела не только безвременный, но и вненациональный характер при таком «вавилонском смешении» различных культурных наслоений.

Однако, несмотря на приведённые детали, новизна прочтения хорошо известного сюжета заключена в принципиально иной мотивации поведения Турандот. Она идентифицирует себя с Лоу-Линг, которая давным-давно была замучена и убита мужчиной, поэтому Турандот движима жаждой мести. Этот мотив не нов в истории интерпретации сюжета. В частности, он присутствует в обработке Ф. Шиллера 1802 года для Веймарского театра. О. Шмитт в подтверждение приводит следующую цитату: «Я вижу по всей Азии женщину / Униженную и обречённую на рабское ярмо, / И я хочу мстить за оскорблённый пол 
этому гордому мужскому люду» (цит. по: [10:59]). Как видно, либреттисты Дж. Пуччини, следуя стремлению композитора придать фьябе К. Гоцци современное звучание, не только переосмыслили характер ведущих женских фигур, но и обобщили многие мотивы исторически сложившихся сюжетных модификаций.

Свой рассказ о постоянно звучащем в ней крике несчастной ЛоуЛинг (2 к., 2 д.) Турандот сопровождает новым облачением, словно бы входя в плоть своей далёкой прародственницы: на платье, фасон которого воссоздаёт осовремененный вариант ханьфу, она надевает его более ранний вариант - свободного покроя до пят, с тяжёлыми фалдами длинных рукавов - и покрывает голову сложным убором из диковинных цветов, напоминающим узорчатую корону принцесс из русских сказок. К концу повести она оказывается как в коконе-панцире, недосягаемая и непобедимая. После этого следует сцена загадок, продвигающая события к поворотному моменту в сюжетных перипетиях и знаменующая своеобразный возвратный ход времени. Режиссёр умножает символическую линию спектакля немым видео А. Китцига. Возникающий параллелизм сценического действия и метаморфоз масок визуализирует психологическую компоненту оперы Дж. Пуччини, раскрытию которой подчиняется весь комплекс сценарно-декорационных средств. Использование М. Марелли маски как особого художественного приёма мотивировано многими причинами. Во-первых, согласно его убеждению, маска олицетворяет тайну; она и скрывающееся за ней лицо «являются многослойными и многозначными, непостижимыми и странными, глубокими и загадочными - как и фигура Турандот» [7:62]. Во-вторых, напоминает о праформах театральной игры; в-третьих, в дальневосточной традиции появление духов оповещало о незавершённом деле либо необходимости отмщения ${ }^{1}$, в силу чего режиссёр усматривал в попытке принцессы спрятать свои «страхи перед мужским началом» за фигурой Лоу-Линг очевидную связь между героинями [8:63]; в-четвёртых, по его словам, «этим масочным лицам присущи черты < ..> трагизма, мучительно-тревожной неразрешимости» [7:62]. В результате, сцена испытания Калафа приобретает

\footnotetext{
1 Этот мотив появился и в западноевропейском театре, достаточно вспомнить «тень отца Гамлета».
} 
иное измерение, очерчивая изгибы судьбы обоих героев. Раз за разом, как чешуя, спадают с Турандот одежды, сопровождаясь трансформацией ранее неодухотворённого лика маски: фантом-надежда отпечатывается иссиня-чёрно-белыми пятнами, придавая ему болезненные черты; огонь в крови сжигает его как папиросную бумагу; двойственность натуры самой Турандот отражается в изморози, под действием которой маска трескается наподобие глиняного слепка и окончательно разрушается. Героиня остаётся в тонком шелковистом платье-рубашке на бретельках и пытается ладонями прикрыть свои оголённые плечи. Её обнажённость сродни беззащитности, утрате почвы под ногами. И когда Калаф прикрывает её своим плащом, становится понятным, что это не просто жест великодушия или снисхождения. Он настроен на равноправное соперничество: ему мало одержанной победы, он хочет её любви и готов ради этого пожертвовать жизнью.

Иной предстаёт Турандот в роковую ночь. Борьба тёмных демонов себялюбия, властности, жестокости в её душе созвучна тревожному времени суток с уговорами, обольщениями, пытками и гибелью Лиу. Белая сорочка девушки, как символ чистоты и непорочности, подчёркивает поблёскивающую черноту одеяния и поступков принцессы. Когда же поцелуй Калафа развеивает последние сомнения Турандот, всё озаряется светом. Описанный сценически-визуальный ряд усиливает накал пуччиниевской музыки. Вот что пишет по этому поводу О. Шмитт: «На спектакле в Брегенце был сыгран финал Альфано в сокращённом варианте, правда, со вставкой из первой версии, где после поцелуя Калафа Турандот оркестр некоторое время звучит, воссоздавая это эмоциональное потрясение. В этом первом варианте говорила она ещё об ужасе, который ощущает. С возгласом “Оставь меня!” она отстраняется от Калафа, однако в том же такте поёт “Нет!..”. Её нерешительность заканчивается в конце концов объятьями неизвестного принца. Лишь только Турандот узнаёт его имя, говорит она своему отцу: "Его имя - любовь!” С такой же силой, как Турандот раньше противилась мужчинам, она теперь страстно любит» [9:25]. Так М. Марелли разрешил не только проблему невозможности разыграть на огромной сцене психологическое перерождение личности традиционными актерскими приёмами, но и противоречия сюжетных поворотов, не дававших покоя композитору. 
Выводы и перспективы. Постановка «Турандот» Дж. Пуччини, осуществлённая М. Марелли, раскрывает «трудный путь познания» режиссёра при создании той концепции, которая становится неотъемлемой частью музыкальной драматургии, делая явными сокрытые в её глубинном слое смыслы. Одновременно опыт брегенцской версии заставляет задуматься о немаловажной роли условий сценического пространства, мыслимого талантливым постановщиком-оформителем одним из компонентов многосоставной системы иерархических соподчинённостей спектакля. В этом видится мастерское соединение личных художественно-эстетических установок М. Марелли, особенностей последнего оперного полотна Дж. Пуччини и всех театральных ресурсов уникальной сцены на Боденском озере. Достигнутая творческим коллективом художественная целостность стала залогом успеха и незабываемых впечатлений публики. Популярность многочисленных оперных фестивалей, которая обеспечивается не только участием блистательных певцов современности, но и неповторимостью режиссёрских решений, открывает путь к постижению новаций в области сценарной драматургии, определяющей облик музыкального театра сегодняшнего дня.

\section{ЛИТЕРАТУРА}

1. Нестьев И. В. Джакомо Пуччини. Очерк жизни и творчества. Москва : Музгиз, 1963. $168 \mathrm{c.}$

2. Нестьева М. И. В противовес произволу «режиссёрского театра». Аспекти історичного музикознавства : зб. наук. $\mathrm{cm}$. / Харків. нац. ун-т мистецтв ім. І. П. Котляревського. Харків, 2013. Вип. 6. С. 272-289.

3. Черкашина-Губаренко М. Р. Оперный театр в пространстве меняющегося мира. Аспекти історичного музикознавства : зб. наук. сm. / Харків. нац. ун-т мистецтв ім. І. П. Котляревського. Харків, 2012. Вип. 5. С. 68-79.

4. Bregenzer Festspiele wurde feierlich eröffnet. Kultur und Freizeit rund um den See. 2015. 31 Juli. S. 4-5.

5. Die Chinesische Mauer im Bodensee. Kultur und Freizeit rund um den See. 2015. 31 Juli. S. 10-11.

6. Marelli M. A. „Stück soll keinen Eventcharakter haben“ : [Interview]. Kultur und Freizeit rund um den See. 2015. 31 Juli. S. 8. 
7. Marelli M. A. An der Idee der Maske... . Turandot Giacomo Puccini : [Die Broschüre]. 2015. 6 Juli. S. 62.

8. Marelli M. A. Wenn ich mir Masken... . Turandot Giacomo Puccini : [Die Broschüre]. 2015. 6 Juli. S. 63.

9. Schmitt O. A. Leben durch die Liebe : Puccinis letzte Oper Turandot. Turandot Giacomo Puccini : [Die Broschüre]. 2015. 6 Juli. S. 22-25.

10. Schmitt O. A. Wandlungen eines Märchens : von Turandocht zu Turandoch. Turandot Giacomo Puccini : [Die Broschüre]. 2015. 6 Juli. S. 56-59.

\section{REFERENCE}

1. Nestev, I. (1963). Dzhakomo Puchchini. Ocherk zhizni i tvorchestva [Giacomo Puccini. Essay on the life and creativity]. Moscow: Muzgiz, 168 p. [in Russian].

2. Nesteva, M. (2013). V protivoves proizvolu «rezhissYorskogo teatra» [In opposition to the free will of the «Director's Theatre»]. Aspekti Istorichnogo muzikoznavstva [Aspects of historical musicology], (6), pp. 272-289. [in Russian].

3. Chercashina-Gubarenko, M. (2012). Opernyiy teatr v prostranstve menyayuschegosya mira [The opera theatre in a space of the world of changes]. Aspekti Istorichnogo muzikoznavstva [Aspects of historical musicology], (5), pp. 6879. [in Russian].

4. Kultur und Freizeit rund um den See (2015). Bregenzer Festspiele wurde feierlich eröffnet. SS. 4-5. [in German].

5. Kultur und Freizeit rund um den See (2015). Die Chinesische Mauer im Bodensee. SS. 10-11. [in German].

6. Marelli, M. (2015). „Stück soll keinen Eventcharakter haben“. Kultur und Freizeit rund um den See, SS. 8. [in German].

7. Marelli, M. (2015). An der Idee der Maske... . Turandot Giacomo Puccini, SS. 62. [in German].

8. Marelli, M. (2015). Wenn ich mir Masken... . Turandot Giacomo Puccini, SS. 63. [in German].

9. Schmitt, O. (2015). Leben durch die Liebe : Puccinis letzte Oper Turandot. Turandot Giacomo Puccini, SS. 22-25. [in German].

10. Schmitt, O. (2015). Wandlungen eines Märchens : von Turandocht zu Turandoch. Turandot Giacomo Puccini, SS. 56-59. [in German].

Стаття надійшла до редакиії 11.01.2019 р. 